\title{
KIAA0319 gene polymorphisms are associated with developmental dyslexia in Chinese Uyghur children
}

\author{
Hua Zhao, Yun Chen, Bao-ping Zhang and Peng-xiang Zuo
}

The gene KIAA0319 has been reported to be associated with developmental dyslexia (DD) in previous studies, although the results have not always been consistent. However, few studies have been conducted in Uyghur populations. In the present study, we aimed to investigate the association of KIAA0319 polymorphisms and DD in individuals of Uyghurian descent. We used a custom-by-design 48-Plex SNPscan Kit to genotype 18 single-nucleotide polymorphisms (SNPs) of KIAA0319 in a group of 196 children with dyslexia and 196 controls of Uyghur descent aged 8-12 years. As a result, 7 SNPs $\left(P_{\min }=0.001\right)$ of $K I A A 0319$ had nominal significant differences between the cases and controls under specific genotypic models. The two SNPs rs6935076 ( $P=0.020$ under dominant model; $P=0.028$ under additive model) and rs3756821 $(P=0.021$ under additive model) remained significantly associated with dyslexia after Bonferroni correction. Linkage disequilibrium analysis showed three blocks within $K I A A 0319$, and only a 10-SNP haplotype in block 3 was present at significantly different frequencies in the dyslexic children and controls. This study indicated that genetic polymorphisms of KIAAO319 are associated with an increased risk of DD in the Uyghur population.

Journal of Human Genetics (2016) 61, 745-752; doi:10.1038/jhg.2016.40; published online 21 April 2016

\section{INTRODUCTION}

Developmental dyslexia (DD) is a complex neuro-genetic disorder associated with an impairment of reading performance despite adequate intelligence and educational opportunities and in the absence of sensory or neurological disability. It is a common reading disability with estimated prevalences of $5-17 \%$ among school-aged children in Western countries ${ }^{1,2}$ and 3.9-8.0\% among those in China. ${ }^{3}$ Although the etiology of dyslexia is not fully clear, a number of studies have shown that genetic factors play an important role in its development. ${ }^{1,4-6}$ To date, nine dyslexia susceptibility loci (DYX1 to DYX9) have been mapped and allocated based on linkage studies. Subsequent association studies have identified several candidate genes at most of these loci, including KIAA0319, ${ }^{1}$ DCDC2, ${ }^{4} D Y X 1 C 1^{5}$ and ROBO1. ${ }^{6}$

KIAA0319 is located on chromosome 6p22.2-22.3. Its association with dyslexia was first proposed by Kaplan et al., ${ }^{7}$ who found a microsatellite marker residing in KIAA0319 according to linkage studies. Since then, dyslexia-KIAA0319 association studies have been conducted in the US, ${ }^{8} \mathrm{UK},{ }^{1,9}$ German, ${ }^{10}$ Canadian, ${ }^{11,12}$ Indian ${ }^{13,14}$ and Chinese $^{15,16}$ populations, suggesting that several single-nucleotide polymorphisms (SNPs) are associated with the risk of reading disability, such as rs4504469, rs6935076 and rs2038137. However, the results have not always been consistent because of genetic and linguistic differences among ethnic groups. KIAA0319 is expressed in the human cerebral neocortex. ${ }^{17}$ The protein encoded by KIAA0319 is a large and highly $\mathrm{N}$-and $\mathrm{O}$-glycosylated plasma membrane protein that is involved in the regulation of neuronal migration and neurite growth through the endocytosis pathway of protein and proteolytic processing, ${ }^{18-20}$ which is considered to be important in the pathophysiology of dyslexia. ${ }^{21,22}$ However, the exact functions of the KIAA0319 protein and the pathogenic mechanisms of dyslexia-associated KIAA0319 polymorphisms remain to be fully elucidated.

Thus far, most studies on dyslexia-associated polymorphisms have been performed in the European and Chinese populations and few have examined individuals of Uyghurian descent. The Uyghur ethnicity numbers about 11 million people and represents the second largest minority ethnic group in China. The Uyghur people mainly live in the Xinjiang Uyghur Autonomous region in the far northwest of China, where they account for $\sim 48 \%$ of the population. ${ }^{23}$ The Uyghur population typically presents a mixed genetic origin, with both Eastern and Western anthropometric traits. ${ }^{24,25}$ Uyghurs have a unique culture, religion and language that are very different from those of other ethnic populations. Here, based on our previous epidemiologic and genetic studies, we performed a case-control association study of an unrelated Chinese Uyghur cohort to investigate whether the previously reported associations between KIAA0319 gene polymorphisms and dyslexia could be replicated in Uyghur children.

\section{MATERIALS AND METHODS}

Experimental subjects

We selected 4251 Uyghur primary school students aged 8-12 years by cluster sampling in Kashgar and Aksu, Xinjiang, China. The study was approved by the ethical committee of the Medical School of Shihezi University. Informed 
written consent was obtained from all participants and their guardians. The diagnostic criteria for dyslexia were based on the following criteria: (1) a score on The Pupil Rating Scale Revised: Screening for Learning Disability of less than 65 points; ${ }^{26}$ (2) a score on The Dyslexia Checklist for Uyghur Children that was at least 2 standard deviations higher than the mean score; ${ }^{27}$ (3) an intelligence quotient score of higher than 80 as assessed using the China-Wechsler Intelligence Scale for Children ${ }^{28}$ and (4) in the absence of visual and/or auditory disorders or psychiatric diseases. In total, 228 Uyghur students were diagnosed as dyslexic and 196 of them participated in the present study, including a total of 126 boys and 70 girls aged $8-12$ years (mean age $=10.99 \pm 1.1$ years). Then, 196 control subjects without dyslexia, assessed based on the same diagnostic criteria, were selected from the initial sample. The dyslexic and control subjects were matched for age, education, gender and ethnicity.

\section{Genotyping}

A total of 18 SNPs of KIAA0319 were selected in the present study for the following reasons. (1) The minor allele frequencies of these 18 SNPs were more than 0.05 according to both the HapMap CHB (Han Chinese in Beijing, China) and the CEU (Utah residents with ancestry from northern and western Europe) data. (2) We selected the SNPs in KIAA0319 based on prior reports of their association with dyslexia in the European and Chinese populations. The SNPs rs4504469, rs2038137, rs6935076, rs2179515, rs3212236, rs761100 and rs9461045 were associated with dyslexia in the European populations. ${ }^{1,9-14}$ The SNPs rs1091031, rs699463, rs3903801, rs12193738, rs2760157, rs807507, rs16889506, rs9366577, rs16889556, rs2038139 and rs3756821 were associated with dyslexia in the Chinese populations. ${ }^{15,16}$

DNA were extracted from oral mucosal cells by the buccal swab method as described elsewhere. ${ }^{29}$ The SNP genotyping work was performed using a custom-by-design 48-Plex SNPscan ${ }^{\mathrm{TM}}$ Kit (Cat\#: G0104K, Genesky, Shanghai, China) as previously described. ${ }^{30}$ This kit was developed according to patented SNP genotyping technology based on double ligation and multiplex fluorescence PCR. Our study data were collected through procedures carried out according to the manufacturer's instructions. Each 96-well plate included 1 non-template control. For quality control, repeated analyses were performed for $4 \%$ of randomly selected samples with high DNA quality. Call rates for each SNP were above $98 \%$.

\section{Statistical analysis}

Hardy-Weinberg equilibrium (HWE) tests were performed for each SNP. Differences in the distribution of demographic characteristics, selected variables and genotypes of the 18 SNPs between the cases and controls were evaluated using the $\chi^{2}$ or $t$-test. The strengths of associations between SNP genotypes and the risk of dyslexia were estimated by computing the odds ratio and their $95 \%$ confidence intervals using logistic regression analyses with dominant, recessive, over-dominant, additive and genotype models. Bonferroni correction was applied for multiple comparisons. The above statistical analyses were performed using SAS 9.1.3 (SAS Institute, Cary, NC, USA) and $P$ values were performed using two-tailed test with a significance level of 0.05 . Linkage disequilibrium (LD) analysis of SNPs and haplotype selection were performed using Haploview software (Version 4.1). ${ }^{31}$ The post-hoc power of the study was estimated using $\mathrm{G}^{\star}$ Power software (version 3.1). ${ }^{32}$

\section{RESULTS}

\section{Characteristics of the Uyghur population}

On the whole, 195 cases and 196 controls were successfully genotyped in the study, with success rates of $99.5 \%$ and $100 \%$, respectively. The characteristics of these Uyghur students are summarized in Table 1. The dyslexia and normal students appeared to be adequately matched on age, sex, education and intelligence quotient scores as suggested by $\chi^{2}$ or $t$-tests $(P>0.05)$. The details of the 18 genotyped SNPs are shown in Table 2. The minor allele frequencies of most SNPs in the control subjects were between the minor allele frequencies of the $\mathrm{CHB}$ and CEU data. All the markers showed HWE $(P>0.05$ for all markers except rs16889506, for which $P=0.022$ ).
Table 1 Distribution of selected demographic variables and risk factors of participants

\begin{tabular}{|c|c|c|c|c|c|c|}
\hline \multirow[b]{2}{*}{ Variable } & \multicolumn{2}{|c|}{ Cases $(n=195)$} & \multicolumn{2}{|c|}{ Control $(n=196)$} & \multirow[b]{2}{*}{$\chi^{2}$} & \multirow[b]{2}{*}{$P$} \\
\hline & $n$ & $\%$ & $n$ & $\%$ & & \\
\hline \multicolumn{5}{|l|}{ Age } & 0.124 & 0.725 \\
\hline$\leqslant 10$ years & 76 & 38.97 & 73 & 37.24 & & \\
\hline$\geqslant 11$ years & 119 & 61.03 & 123 & 62.76 & & \\
\hline \multicolumn{5}{|l|}{ Sex } & 0.346 & 0.556 \\
\hline Boys & 125 & 64.10 & 120 & 61.22 & & \\
\hline Girls & 70 & 35.90 & 76 & 38.78 & & \\
\hline \multicolumn{5}{|l|}{ Grade } & 0.005 & 0.998 \\
\hline Three & 56 & 28.72 & 56 & 28.57 & & \\
\hline Four & 69 & 35.38 & 70 & 35.71 & & \\
\hline Five & 70 & 35.90 & 70 & 35.71 & & \\
\hline IQ score ${ }^{a}$ & \multicolumn{2}{|c|}{$94.12 \pm 12.85$} & \multicolumn{2}{|c|}{$93.80 \pm 12.47$} & 0.352 & 0.295 \\
\hline
\end{tabular}

Abbreviation: $I Q$, intelligence quotient.

a $Q$ scores were represented as mean \pm standard deviation and statistical analysis was performed using Student's $t$-test.

Associations between 18 polymorphisms and the risk of dyslexia In the present study, 7 of the 18 KIAA0319 polymorphisms showed nominal associations with dyslexia after genotyping (Supplementary Table 1). As Table 3 indicated, allelic frequencies of 6 SNPs (rs1091031: $P=0.034$; rs16889556: $P=0.010$; rs6935076: $P=0.001$; rs3756821: $P=0.001 ;$ rs3212236: $P=0.009$; rs9461045: $P=0.009$ ) were significantly different between the dyslexia and control subjects. Furthermore, the minor allele $(\mathrm{T})$ frequency of rs6935076 $(P=0.026)$ and T allele of rs3756821 $(P=0.023)$ also displayed strong associations with dyslexia after applying Bonferroni's correction.

Table 3 also shows genotype distributions under various models of these seven risk SNPs. The results showed a significant association of rs1091031 in the dominant $(P=0.042)$ and additive $(P=0.033)$ models. The SNP rs9366577 demonstrated a nominal significant association in the over-dominant model $(P=0.024)$. SNP rs16889556 showed a significant association in the dominant $(P=0.007)$, over-dominant $(P=0.012)$ and additive $(P=0.009)$ models and in the co-dominant model for the heterozygous genotype (CT vs CC: $P=0.010)$. Similarly, SNP rs6935076 manifested a nominal association in the dominant $(P=0.001)$, over-dominant $(P=0.009)$ and additive $(P=0.001)$ models as well as in the co-dominant model (CT vs CC: $P=0.003$; TT vs CC: $P=0.046$ ). A significant association was also found for rs3756821 in the dominant $(P=0.004), \quad$ recessive $\quad(P=0.021)$, additive $\quad(P=0.001)$ and co-dominant models (CT vs CC: $P=0.021$; TT vs CC: $P=0.004$ ). Moreover, SNP rs3212236 and rs9461045 showed equally significant associations under the dominant $(P=0.019)$ and additive $(P=0.010)$ models, as well as in the co-dominant model for the homozygous genotype (TT vs CC: $P=0.015)$. However, after Bonferroni correction for multiple comparisons in different models, only the SNP rs6935076 under the dominant $(P=0.020)$ and additive $(P=0.028)$ models, as well as rs3756821 under the additive model $(P=0.021)$, remained significantly different between dyslexic and control subjects.

\section{Haplotype analysis}

The SNP rs16889506 was out of HWE, so it was excluded from the haplotype analysis. LD analysis was conducted for 17 SNPs, and three LD blocks within KIAA0319 were detected according to the calculated $D^{\prime}$ values, as shown in Figure 1. In block 3, there were five common haplotypes constituted by 10 SNPs (ordered by frequency as 
Table 2 List of SNPs and HWEs of KIAAO319 analyzed by SNPscan in the present study

\begin{tabular}{|c|c|c|c|c|c|c|c|}
\hline$S N P$ & $D B^{a}$ & Allele & Position & Location & $C H B / C E U^{b} M A F$ & Control MAF & HWE \\
\hline rs1091031 & No data & $\mathrm{G} / \mathrm{A}$ & 24539139 & 3 'downstream & $0.193 / 0.438$ & 0.298 & 1.000 \\
\hline rs699463 & 4 & $\mathrm{G} / \mathrm{A}$ & 24544903 & Exon21 & $0.121 / 0.239$ & 0.184 & 1.000 \\
\hline rs3903801 & 5 & $A / G$ & 24559433 & Intron 16 & $0.246 / 0.429$ & 0.327 & 0.330 \\
\hline rs12193738 & No data & $\mathrm{T} / \mathrm{C}$ & 24568393 & Intron 13 & $0.215 / 0.473$ & 0.324 & 0.145 \\
\hline rs2760157 & 5 & $\mathrm{G} / \mathrm{A}$ & 24578272 & Exon 9 & $0.489 / 0.183$ & 0.332 & 0.262 \\
\hline rs807507 & No data & $\mathrm{C} / \mathrm{G}$ & 24579867 & Intron 8 & $0.178 / 0.483$ & 0.309 & 0.093 \\
\hline rs4504469 & No data & $\mathrm{C} / \mathrm{T}$ & 24588884 & Exon 4 & 0.019/0.306 & 0.250 & 0.339 \\
\hline rs16889506 & $1 f$ & $\mathrm{~T} / \mathrm{C}$ & 24595853 & Intron 3 & $0.109 / 0.186$ & 0.219 & 0.022 \\
\hline rs2179515 & No data & $\mathrm{C} / \mathrm{T}$ & 24628203 & Intron 1 & $0.113 / 0.385$ & 0.265 & 0.714 \\
\hline rs761100 & 6 & $C / A$ & 24632642 & Intron 1 & $0.130 / 0.455$ & 0.304 & 0.502 \\
\hline rs9366577 & No data & $\mathrm{T} / \mathrm{C}$ & 24641328 & Intron 1 & $0.073 / 0.150$ & 0.082 & 0.120 \\
\hline rs16889556 & No data & $\mathrm{C} / \mathrm{T}$ & 24641605 & Intron 1 & $0.201 / 0.155$ & 0.122 & 1.000 \\
\hline rs6935076 & 5 & $\mathrm{C} / \mathrm{T}$ & 24644322 & Intron 1 & $0.230 / 0.262$ & 0.212 & 0.668 \\
\hline rs2038139 & No data & $\mathrm{A} / \mathrm{C}$ & 24645420 & Intron 1 & $0.122 / 0.332$ & 0.265 & 1.000 \\
\hline rs2038137 & $2 b$ & $\mathrm{G} / \mathrm{T}$ & 24645943 & 5' UTR & $0.234 / 0.334$ & 0.265 & 1.000 \\
\hline rs3756821 & 4 & $\mathrm{C} / \mathrm{T}$ & 24646821 & 5' UTR & $0.411 / 0.362$ & 0.276 & 0.593 \\
\hline rs3212236 & 5 & $\mathrm{~T} / \mathrm{C}$ & 24648455 & Promoter & $0.358 / 0.358$ & 0.452 & 0.774 \\
\hline rs9461045 & No data & $\mathrm{C} / \mathrm{T}$ & 24649061 & Promoter & $0.481 / 0.221$ & 0.452 & 0.774 \\
\hline
\end{tabular}

Abbreviations: HWE, Hardy-Weinberg equilibrium; MAF, Minor allele frequency; SNP, single-nucleotide polymorphism; UTR, untranslated region.

aRegulome DB score, http://www.regulomedb.org/.

${ }^{b} \mathrm{CHB} / \mathrm{CEU}$ : Han Chinese in Beijing, China/Utah residents with ancestry from northern and western Europe.

The bold entries indicate the $P<0.05$.

CCTCCAGCCT > TATCCCTCTC > CCCCTAGTTC > CCTTTAG TTC $>$ CATCCAGTTC) and the frequency of the haplotype CCTTTA GTTC in the dyslexic group was significantly higher than that in the control group $(P=0.002)$. Another haplotype, CCCCTAGTTC, in block 3 showed a trend toward significance in the haplotype-level logistic regression analyses $(P=0.043)$. We did not find any significant haplotypes in the other two LD blocks (Table 4).

\section{Power of the study}

Given the significant associations of seven polymorphisms of KIAA0319 with dyslexia in our sample, it was necessary to estimate whether our study had adequate power to detect the true associations of variants in the Uyghur populations. We estimated the power of our study using the effect size (log of odds ratio) of the seven candidate dyslexia-associated SNPs of KIAA0319. Given an effect size of 0.140 ( $\log$ of 1.381) for the SNP rs1091031, with the alpha value of 0.05 and our study sample of 391 subjects, we calculated the power for detecting a significant association with this SNP as $81.9 \%$ (Table 3). Similarly, our post-hoc calculation showed that the levels of power for detecting associations of the SNPs rs9366577, rs16889556, rs6935076, rs3756821, rs3212236 and rs 9461045 with dyslexia were $84.0 \%, 99.5 \%$, $99.6 \%, 99.2 \%, 92.8 \%$ and $92.8 \%$, respectively. These results showed that our sample size of 391 provided adequate power $(>80 \%)$ to detect associations between SNPs of KIAA0319 and dyslexia in the Uyghur population.

\section{DISCUSSION}

To date, there have been numerous studies focused on dyslexia-associated KIAA0319 polymorphisms. However, these studies have mainly been performed in the European, Indian and Han Chinese populations and the results have often been inconclusive. Taking the genetic and linguistic differences between the Uyghur population and other populations into consideration, we selected 18 SNPs of KIAA0319 and performed high-throughput sequencing to assess the association of these polymorphisms with dyslexia in an unrelated Uyghur cohort. In summary, we identified that seven KIAA0319 polymorphisms and two haplotypes had nominal associations with dyslexia after genotyping. After performing Bonferroni correction for multiple comparisons, the associations of rs3756821 and rs6935076 with dyslexia remained significant. Moreover, post-hoc power calculations indicated that our sample size of 391 had adequate power to detect the true association of variants in KIAA0319 with dyslexia. To our knowledge, this study is first to have explored the role of KIAA0319 in dyslexia in the Uyghur population.

The present study demonstrated that SNPs in KIAA0319 were indeed associated with the risk of dyslexia in the Uyghur population. Although the function of this gene is poorly understood, several studies have shown that it is related to impaired neuronal migration and intercellular adhesion. ${ }^{17-20}$ Researchers have explored the functions of KIAA0319 through several methods, such as using functional magnetic resonance imaging and animal models. Paracchini et al. ${ }^{17}$ used in situ hybridization and reported the pattern of KIAA0319 expression in the developing cerebral neocortex of rat and human fetuses. Furthermore, previous studies showed that the genetic knockdown or in utero small interfering RNA (siRNA) interference of KIAA0319 could disrupt neuronal migration in rodents and result in impairments of the primary auditory cortex and reductions in the midsagittal area of the corpus callosum, ${ }^{34-36}$ which has been reported to be related to processing deficits in humans. ${ }^{37}$ Taken together, these data suggest a direct link between a specific KIAA0319 genetic background and a biological mechanism leading to dyslexia. The role of KIAA0319 in dyslexia is also supported by the recognition of a single variant or haplotypes associated with dyslexia and affecting the gene expression of KIAA0319.

A growing body of evidence has pointed to the association of KIAA0319 polymorphisms with dyslexia in the Chinese population. Among these polymorphisms, 11 KIAA0319 variations were genotyped in the present study, and nominally significant associations were detected between 4 SNPs (rs1091031, rs9366577, rs16889556 and rs3756821) and dyslexia. Among these SNPs, only rs3756821 retained a significant association with dyslexia after Bonferroni correction. The SNP rs3756821 is located in the 5' UTR of KIAA0319 and showed a 
Table 3 Logistic regression analyses of associations between KIAAO319 polymorphisms and risk of dyslexia

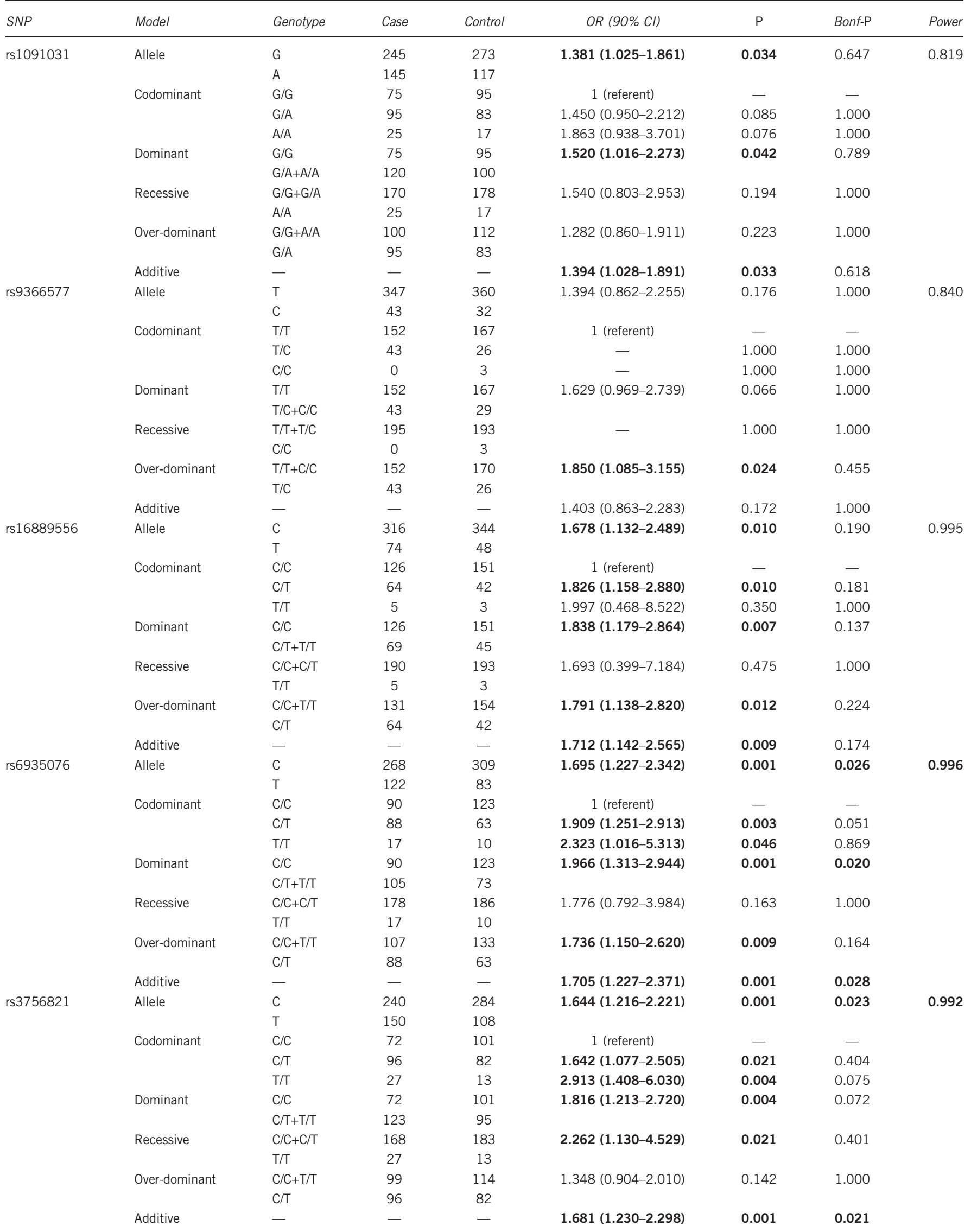


Table 3 (Continued)

\begin{tabular}{|c|c|c|c|c|c|c|c|c|}
\hline$S N P$ & Model & Genotype & Case & Control & OR $(90 \% \mathrm{Cl})$ & $\mathrm{P}$ & Bonf-P & Power \\
\hline \multirow[t]{12}{*}{ rs3212236 } & \multirow[t]{2}{*}{ Allele } & $\mathrm{T}$ & 250 & 215 & $0.680(0.511-0.906)$ & 0.009 & 0.162 & \multirow[t]{12}{*}{0.928} \\
\hline & & $\mathrm{C}$ & 140 & 177 & & & & \\
\hline & \multirow[t]{3}{*}{ Codominant } & $\mathrm{T} / \mathrm{T}$ & 82 & 60 & 1 (referent) & - & - & \\
\hline & & $\mathrm{T} / \mathrm{C}$ & 86 & 95 & $0.662(0.425-1.031)$ & 0.068 & 1.000 & \\
\hline & & $\mathrm{C} / \mathrm{C}$ & 27 & 41 & $0.482(0.267-0.868)$ & 0.015 & 0.287 & \\
\hline & \multirow[t]{2}{*}{ Dominant } & $\mathrm{T} / \mathrm{T}$ & 82 & 60 & \multirow[t]{2}{*}{$0.608(0.401-0.922)$} & \multirow[t]{2}{*}{0.019} & \multirow[t]{2}{*}{0.362} & \\
\hline & & $\mathrm{T} / \mathrm{C}+\mathrm{C} / \mathrm{C}$ & 113 & 136 & & & & \\
\hline & \multirow[t]{2}{*}{ Recessive } & $\mathrm{T} / \mathrm{T}+\mathrm{T} / \mathrm{C}$ & 168 & 155 & \multirow[t]{2}{*}{$0.608(0.357-1.035)$} & \multirow[t]{2}{*}{0.067} & \multirow[t]{2}{*}{1.000} & \\
\hline & & $\mathrm{C} / \mathrm{C}$ & 27 & 41 & & & & \\
\hline & \multirow[t]{2}{*}{ Over-dominant } & $\mathrm{T} / \mathrm{T}+\mathrm{C} / \mathrm{C}$ & 109 & 101 & \multirow[t]{2}{*}{$0.839(0.563-1.249)$} & \multirow[t]{2}{*}{0.387} & \multirow[t]{2}{*}{1.000} & \\
\hline & & $\mathrm{T} / \mathrm{C}$ & 86 & 95 & & & & \\
\hline & Additive & - & - & - & $0.688(0.518-0.915)$ & 0.010 & 0.193 & \\
\hline \multirow[t]{12}{*}{ rs9461045 } & \multirow[t]{2}{*}{ Allele } & $\mathrm{C}$ & 250 & 215 & \multirow[t]{2}{*}{$0.680(0.511-0.906)$} & \multirow[t]{2}{*}{0.009} & \multirow[t]{2}{*}{0.162} & \multirow[t]{12}{*}{0.928} \\
\hline & & $\mathrm{T}$ & 140 & 177 & & & & \\
\hline & \multirow[t]{3}{*}{ Codominant } & $\mathrm{C} / \mathrm{C}$ & 82 & 60 & 1 (referent) & - & - & \\
\hline & & $\mathrm{C} / \mathrm{T}$ & 86 & 95 & $0.662(0.425-1.031)$ & 0.068 & 1.000 & \\
\hline & & $\mathrm{T} / \mathrm{T}$ & 27 & 41 & $0.482(0.267-0.868)$ & 0.015 & 0.287 & \\
\hline & \multirow[t]{2}{*}{ Dominant } & $\mathrm{C} / \mathrm{C}$ & 82 & 60 & \multirow[t]{2}{*}{$0.608(0.401-0.922)$} & \multirow[t]{2}{*}{0.019} & \multirow[t]{2}{*}{0.362} & \\
\hline & & $\mathrm{C} / \mathrm{T}+\mathrm{T} / \mathrm{T}$ & 113 & 136 & & & & \\
\hline & \multirow[t]{2}{*}{ Recessive } & $\mathrm{C} / \mathrm{C}+\mathrm{C} / \mathrm{T}$ & 168 & 155 & \multirow[t]{2}{*}{$0.608(0.357-1.035)$} & \multirow[t]{2}{*}{0.067} & \multirow[t]{2}{*}{1.000} & \\
\hline & & $\mathrm{T} / \mathrm{T}$ & 27 & 41 & & & & \\
\hline & \multirow[t]{2}{*}{ Over-dominant } & $\mathrm{C} / \mathrm{C}+\mathrm{T} / \mathrm{T}$ & 109 & 101 & $0.839(0.563-1.249)$ & 0.387 & 1.000 & \\
\hline & & $\mathrm{C} / \mathrm{T}$ & 86 & 95 & & & & \\
\hline & Additive & - & - & - & $0.688(0.518-0.915)$ & 0.010 & 0.193 & \\
\hline
\end{tabular}

Abbreviations: $\mathrm{Cl}$, confidence interval; OR, odds ratio; SNP, single-nucleotide polymorphism.

The bold entries indicate the $P<0.05$.

nominal association with dyslexia in recent studies on the Chinese population but failed to show a significant association after Bonferroni correction in those studies. ${ }^{15,16}$ These results may imply that rs3756821 represents a risk-associated SNP for dyslexia in the Uyghur populations but not in the Chinese populations. This may be attributed to the genetic and linguistic differences among the Uyghur and Chinese populations, which could mean that genetic susceptibility to dyslexia occurs through different mechanisms. ${ }^{38}$ Compared with the Chinese, Uyghurs form an isolated genetic group because the Uyghur population has been less genetically influenced by recent migration, ${ }^{24}$ which is partly because the Uyghurs are overwhelmingly Muslim and prohibit marriage to non-Muslims. ${ }^{39}$ The Uyghur language belongs to the Altaic family and uses a linear onedimensionally arranged alphabet. ${ }^{40}$ The linguistic characteristics of the Uyghur language are highly dissimilar from those of the Chinese, which is an ideographic language. ${ }^{41}$ Besides, previous studies have found that the cerebral regions activated by speaking the Uyghur and Chinese languages are not identical and identified that the left anterior cingulate gyrus might be particularly associated with the Uyghur language. ${ }^{40}$ However, the functions of SNP rs3756821 and the other four variants identified as candidate dyslexia-associated polymorphisms in the present study are still unclear. These polymorphisms are located either in the 5' UTR, 3' downstream region or in the intron 1 of KIAA0319, which are regions that indirectly modulate gene expression and thereby alter protein expression of KIAA0319 in both neuronal and non-neuronal cell lines, thereby affecting the development of dyslexia. ${ }^{42}$

This study examined polymorphisms that have been frequently reported as having associations with dyslexia by previous studies on Indo-European populations. We genotyped seven SNPs and found nominally significant associations of three SNPs (rs6935076, rs3212236 and rs9461045) with dyslexia. However, only rs6935076 remained significantly associated after Bonferroni correction for multiple testing. These results are consistent with those of a study by Cope et al. ${ }^{1}$ that provided strong evidence for an association of rs6935076 with dyslexia in the UK population. ${ }^{1}$ The SNP rs6935076 is located in intron 1 of KIAA0319 and although no functional evidence is available, it can be speculated that rs6935076 may modulate gene expression. $^{42}$ In addition, a two-SNP haplotype (rs4504469 and rs6935076) was identified by Cope et al. ${ }^{1}$ as being significantly associated with dyslexia in the UK population. ${ }^{1}$ Our study attempted to replicate this finding, but found no association of this haplotype with dyslexia in the Uyghur population $(P=0.167)$. Likewise, rs4504469 (one of the two SNPs in the haplotype identified by Cope et al.) has been reported elsewhere to display a significant association with dyslexia in samples from the UK, German and Indian populations. ${ }^{1,13,14,38}$ We failed to replicate this result in our Uyghur subjects. Previous studies have identified rs4504469 as being associated with dyslexia. The SNP rs4504469 is a nonsynonymous SNP that could result in an amino-acid substitution from alanine to threonine, suggesting an effect on protein function that could promote the development of dyslexia. ${ }^{1,13,43}$ The genetic and linguistic differences between the Uyghur and Indo-European populations could also account for the differences in the associated susceptibility variants. We have mentioned that Uyghurs typically present a mixed genetic origin, with approximately $60 \%$ and $40 \%$ of European and East Asian ancestry, respectively. ${ }^{24,25}$ Although the Uyghur and English languages are both alphabetic languages, Uyghur has distinct written forms and rules for writing and it is more complex overall than English. ${ }^{41}$ Given the functional differences in the activation of brain regions with the use of different languages, the underlying mechanisms of dyslexia might also differ between people of Indo-European and Uyghur 


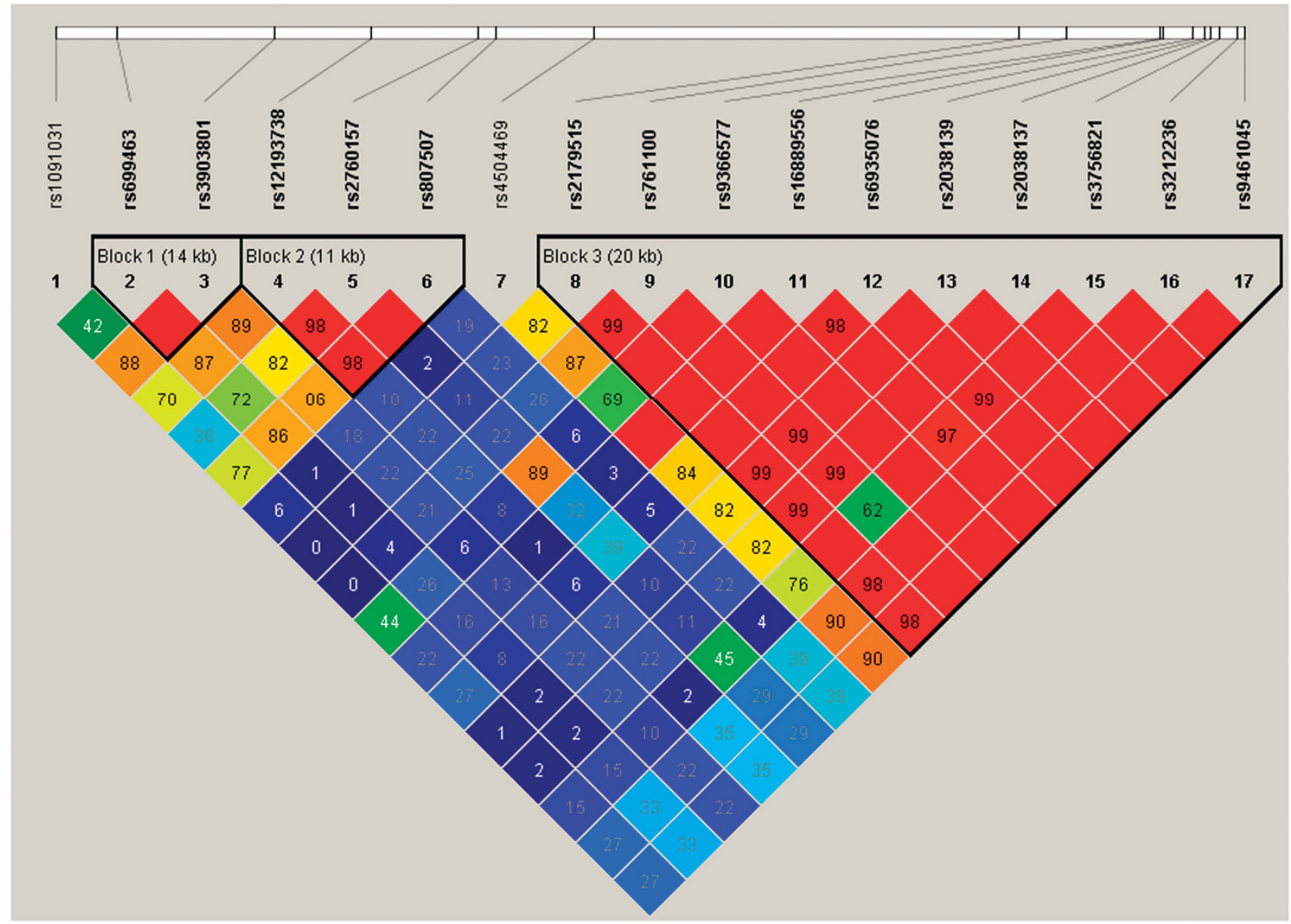

Figure 1 Linkage disequilibrium (LD) block generated by Haploview 4.1 software. Regions of low-to-high LD, as measured by the $D^{\prime}$ statistic, were represented by deep blue to red shading, respectively. LD blocks were analyzed using an algorithm designed by Gabriel et al. ${ }^{33}$

Table 4 Selected haplotype analysis results for the potential association between KIAAO319 and dyslexia

\begin{tabular}{lrrrcc}
\hline Haplotype & Frequency & Case & Control & OR $(95 \%$ Cl $)$ & P-value \\
\hline Block 1: rs699463-rs3903801 & & & & \\
GA & 0.488 & 190 & 192 & - & - \\
GG & 0.309 & 114 & 128 & $0.895(0.648-1.236)$ & 0.502 \\
AA & 0.202 & 86 & 72 & $1.201(0.828-1.742)$ & 0.335
\end{tabular}

Block 2: rs12193738-rs2760157-rs807507

$\begin{array}{llllcc}\text { TGC } & 0.379 & 159 & 136 & - & - \\ \text { TAC } & 0.304 & 110 & 129 & 0.729(0.518-1.027) & 0.071 \\ \text { CGG } & 0.302 & 115 & 121 & 0.813(0.577-1.145) & 0.236\end{array}$

Block 3: rs2179515-rs761100-rs9366577-rs16889556-rs6935076-rs2038139rs2038137-rs3756821-rs3212236-rs9461045

$\begin{array}{lrrrccc}\text { CCTCCAGCCT } & 0.404 & 140 & 176 & - & - \\ \text { TATCCCTCTC } & 0.251 & 93 & 103 & 1.135(0.794-1.623) & 0.487 \\ \text { CCTTTAGTTC } & 0.153 & 73 & 47 & 1.953(1.272-2.997) & \mathbf{0 . 0 0 2} \\ \text { CCCCTAGTTC } & 0.096 & 43 & 32 & 1.689(1.016-2.809) & \mathbf{0 . 0 4 3} \\ \text { CATCCAGTTC } & 0.037 & 15 & 14 & 1.347(0.629-2.884) & 0.443\end{array}$

Abbreviations: $\mathrm{Cl}$, confidence interval; OR, odds ratio.

The bold entries indicate the $P<0.05$.

ancestries. Another two SNPs, rs3212236 and rs9461045, are located in the promoter region of KIAA0319 and showed nominal associations with dyslexia in our Uyghur sample. Previous studies using luciferase constructs demonstrated that these two SNPs could alter reporter gene expression in both neuronal and non-neuronal cell lines; in particular, rs9461045 could create a binding site for the transcriptional repressor octamer-1 (OCT-1). ${ }^{42,44}$

It is generally believed that combined variants within a gene may provide a more comprehensive evaluation than single polymorphisms in association studies. ${ }^{45}$ Based on our haplotypic analysis, we think that the susceptibility haplotype CCTTTAGTTC, which is constructed by 10 SNPs, has an independent effect on dyslexia $(P=0.002)$, whereas haplotype CCCCTAGTTC showed a trend toward a significant difference in frequency between the children with dyslexia and the controls $(P=0.043)$. However, we should be cautious of relying on these results to assess the associations between these haplotypes and dyslexia, because Fallin et al. ${ }^{46}$ suggested that deviation from HWE with a high level of heterozygosity may produce false positive associations with haplotypes. Therefore, we concluded that children who carry more risk alleles are more likely to develop dyslexia than those who carry fewer or no risk alleles.

Although the present study provides valuable insights into genetic associations with dyslexia in an ethnic minority group, several limitations need to be addressed. First of all, the selection of SNPs was based on a previous study, and we devoted ourselves to determining whether these polymorphisms show the same associations in dyslexic Uyghur children, which may not provide a comprehensive picture of the total genetic variability of KIAA0319 in the Uyghur population. Second, the moderate sample size could have limited the 
statistical power of this study. Of the dyslexic Uyghur children who were identified as potential participants in the present study, only $86 \%$ consented to participate in the study, because the people of the Uyghur culture often refuse to take part in procedures involving scraping of the oral mucosa. Moreover, dyslexia has a multifactorial etiology and the interaction between environmental factors and dyslexia susceptibility loci, as well as that between different candidate genes, must be further validated in the Uyghur population.

In conclusion, we performed a study on the association of KIAA0319 with dyslexia in an unrelated Uyghur cohort through SNP selection and genotyping. Our study suggested that seven polymorphisms and two haplotypes of KIAA0319 showed nominal significant associations with the risk of dyslexia. Among these SNPs, rs6935076 and rs3756821 remained significantly associated with dyslexia after Bonferroni correction. The results could contribute to the early identification and management of Uyghur children with dyslexia, as well as assisting future research into dyslexia and the differences between ethnicities regarding genetic susceptibility to disease. Moreover, to better explicate the roles of KIAA0319 in dyslexia etiology and pathology, more functional studies need to be conducted in the Uyghur population.

\section{CONFLICT OF INTEREST}

The authors declare no conflict of interest.

\section{ACKNOWLEDGEMENTS}

This study was supported in part by the National Natural Science Foundation of China (81360434). We thank Dr Da Ding and Dr Yan Liu (Genesky Biotechnologies, Shanghai, China) for providing technical support.

1 Cope, N., Harold, D., Hill, G., Moskvina, V., Stevenson, J., Holmans, P. et al. Strong evidence that KIAAO319 on chromosome $6 \mathrm{p}$ is a susceptibility gene for developmental dyslexia. Am. J. Hum. Genet. 76, 581-591 (2005).

2 Pennington, B. F. \& Bishop, D. V. Relations among speech, language, and reading disorders. Annu. Rev. Psychol. 60, 283-306 (2009).

3 Sun, Z., Zou, L., Zhang, J., Mo, S., Shao, S., Zhong, R. et al. Prevalence and associated risk factors of dyslexic children in a middle-sized city of China: a cross-sectional study. PLOS ONE 8, e56688 (2013)

4 Meng, H., Smith, S. D., Hager, K., Held, M., Liu, J., Olson, R. K. et al. DCDC2 is associated with reading disability and modulates neuronal development in the brain. Proc. Natl Acad. Sci. USA 102, 17053-17058 (2005).

5 Taipale, M., Kaminen, N., Nopola-Hemmi, J., Haltia, T., Myllyluoma, B., Lyytinen, H. et al. A candidate gene for developmental dyslexia encodes a nuclear tetratricopeptide repeat domain protein dynamically regulated in brain. Proc. Natl Acad. Sci. USA 100, 11553-11558 (2003)

6 Hannula-Jouppi, K., Kaminen-Ahola, N., Taipale, M., Eklund, R., Nopola-Hemmi, J., Kaariainen, $\mathrm{H}$. et al. The axon guidance receptor gene $R O B O 1$ is a candidate gene for developmental dyslexia. PLOS Genet. 1, 467-474 (2005).

7 Kaplan, D. E., Gayan, J., Ahn, J., Won, T. W., Pauls, D., Olson, R. K. et al. Evidence for linkage and association with reading disability, on 6p21.3-22. Am. J. Hum. Genet. 70, 1287-1298 (2002).

8 Francks, C., Paracchini, S., Smith, S. D., Richardson, A. J., Scerri, T. S., Cardon, L. R. et al. A 77-kilobase region of chromosome 6 p22.2 is associated with dyslexia in families from the United Kingdom and from the United States. Am. J. Hum. Genet. 75, 1046-1058 (2004).

9 Harold, D., Paracchini, S., Scerri, T., Dennis, M., Cope, N., Hill, G. et al. Further evidence that the KIAA0319 gene confers susceptibility to developmental dyslexia. Mol. Psychiatry 11, 1085-1091 1061 (2006).

10 Ludwig, K. U., Roeske, D., Schumacher, J., Schulte-Körne, G., König, I. R., Warnke, A. et al. Investigation of interaction between DCDC2 and KIAAO319 in a large German dyslexia sample. J. Neural. Transm. 115, 1587-1589 (2008).

11 Couto, J. M., Livne-Bar, I., Huang, K., Xu, Z., Cate-Carter, T., Feng, Y. et al. Association of reading disabilities with regions marked by acetylated $\mathrm{H} 3$ histones in KIAAO319. Am. J. Med. Genet. B Neuropsychiatr. Genet. 153B, 447-462 (2010).

12 Elbert, A., Lovett, M. W., Cate-Carter, T., Pitch, A., Kerr, E. N. \& Barr, C. L. Genetic variation in the KIAA03195' region as a possible contributor to dyslexia. Behav. Genet. 41, 77-89 (2011)
13 Venkatesh, S. K., Siddaiah, A., Padakannaya, P. \& Ramachandra, N. B. An examination of candidate gene SNPs for dyslexia in an Indian sample. Behav. Genet. 41 105-109 (2011).

14 Venkatesh, S. K., Siddaiah, A., Padakannaya, P. \& Ramachandra, N. B. Analysis of genetic variants of dyslexia candidate genes KIAAO319 and DCDC2 in Indian population. J. Hum. Genet. 58, 531-538 (2013).

15 Lim, C. K., Wong, A. M., Ho, C. S. \& Waye, M. M. A common haplotype of KIAAO319 contributes to the phonological awareness skill in Chinese children. Behav. Brain. Funct. 10, 23-23 (2014).

16 Sun, Y., Gao, Y., Zhou, Y., Chen, H., Wang, G., Xu, J. et al. Association study of developmental dyslexia candidate genes DCDC2 and KIAAO319 in Chinese population. Am. J. Med. Genet. B Neuropsychiatr. Genet 165B, 627-634 (2014).

17 Paracchini, S., Thomas, A., Castro, S., Lai, C., Paramasivam, M., Wang, Y. et al. The chromosome $6 \mathrm{p} 22$ haplotype associated with dyslexia reduces the expression of KIAA0319, a novel gene involved in neuronal migration. Hum. Mol. Genet. 15, 1659-1666 (2006).

18 Velayos-Baeza, A., Toma, C., Paracchini, S. \& Monaco, A. P. The dyslexia-associated gene KIAAO319 encodes highly $\mathrm{N}$ - and $\mathrm{O}$-glycosylated plasma membrane and secreted isoforms. Hum. Mol. Genet. 17, 859-871 (2008).

19 Levecque, C., Velayos-Baeza, A., Holloway, Z. G. \& Monaco, A. P. The dyslexiaassociated protein KIAA0319 interacts with adaptor protein 2 and follows the classical clathrin-mediated endocytosis pathway. Am. J. Physiol. Cell. Physiol. 297, C160-C168 (2009).

20 Velayos-Baeza, A., Levecque, C., Kobayashi, K., Holloway, Z. G. \& Monaco, A. P. The dyslexia-associated KIAA0319 protein undergoes proteolytic processing with gamma-secretase-independent intramembrane cleavage. J. Biol. Chem. 285, 40148-40162 (2010)

21 Gabel, L. A., Gibson, C. J., Gruen, J. R. \& LoTurco, J. J. Progress towards a cellular neurobiology of reading disability. Neurobiol. Dis. 38, 173-180 (2010).

22 Poelmans, G., Buitelaar, J., Pauls, D. \& Franke, B. A theoretical molecular network for dyslexia: integrating available genetic findings. Mol. Psychiatry 16, 365-382 (2011).

23 Statistic Bureau of Xinjiang Uyghur Autonomous Region. Available at http://www.xjtj. gov.cn/sjcx Accessed 5 April 2015

24 Black, M. L., Wise, C.A., Wang, W. \& Bittles, A. H. Combining genetics and population history in the study of ethnic diversity in the People's Republic of China. Hum. Biol. 78, 277-293 (2006).

25 Wei, W., Wise, C., Baric, T., Black, M. L. \& Bittles, A. H. The origins and genetic structure of three co-resident Chinese Muslim populations: the Salar, Bo'an and Dongxiang. Hum. Genet. 113, 244-252 (2003).

26 Jin, J., Ryoko, M., Yan, H., Gui-fen, D., Xu, H. \& Xue-bin, C. The revision and appraisal of the pupil rating scale revised-screening for learning disabilities. Chin. J. Child Care 6, 197-200 (1998).

27 Han-rong, W., Ran-ran, S. \& Bing, Y. Preliminary establishment of Dyslexia Checklist for Chinese Children scale. Chin. J. Hum. Genet. 27, 189-190 (2006).

28 Yao-xian, G. \& Xiao-yang, D. The test analysis of China-Wechsler Young Children Scale of Intelligence. Psychology 4, 364-376 (1988).

29 Peng-xiang, Z., Han-rong, W., Zeng-chun, L., Xu-dong, C., Li-juan, P., Lan, Y. et al. Association of polymorphisms in the $D C D C 2$ gene with developmental dyslexia in the Han Chinese. Chin. Med. J. 125, 622-625 (2012).

30 Chen, X., Li, S., Yang, Y., Yang, X., Liu, Y., Liu, Y. et al. Genome-wide association study validation identifies novel loci for atherosclerotic cardiovascular disease. J. Thromb. Haemost. 10, 1508-1514 (2012).

31 Barrett, J. C., Fry, B., Maller, J. \& Daly, M. J. Haploview: analysis and visualization of LD and haplotype maps. Bioinformatics 21, 263-265 (2005)

32 Faul, F., Erdfelder, E., Buchner, A. \& Lang, A. G. Statistical power analyses using G*Power 3.1: tests for correlation and regression analyses. Behav. Res. Methods 41, 1149-1160 (2009).

33 Gabriel, S. B., Schaffner, S. F., Nguyen, H., Moore, J. M., Roy, J., Blumenstiel, B. et al The structure of haplotype blocks in the human genome. Science 296, 2225-2229 (2002).

34 Szalkowski, C. E., Fiondella, C. G., Galaburda, A. M., Rosen, G. D., Loturco, J. J. \& Fitch, R. H. Neocortical disruption and behavioral impairments in rats following in utero RNAi of candidate dyslexia risk gene Kiaa0319. Int. J. Dev. Neurosci. 30, 293-302 (2012).

35 Centanni, T. M., Booker, A. B., Sloan, A. M., Chen, F., Maher, B. J., Carraway, R. S. et al. Knockdown of the dyslexia-associated gene Kiaa0319 impairs temporal responses to speech stimuli in rat primary auditory cortex. Cereb. Cortex 24, 1753-1766 (2014).

36 Szalkowski, C. E., Fiondella, C. F., Truong, D. T., Rosen, G. D., LoTurco, J. J. \& Fitch, R. H. The effects of KiaaO319 knockdown on cortical and subcortical anatomy in male rats. Int. J. Dev. Neurosci. 31, 116-122 (2013).

37 Paul, L. K. Developmental malformation of the corpus callosum: a review of typical callosal development and examples of developmental disorders with callosal involvement. J. Neurodev. Disord. 3, 3-27 (2011).

38 Kirsten, H., Wilcke, A., Ligges, C., Boltze, J. \& Ahnert, P. Association study of a functional genetic variant in KIAAO319 in German dyslexics. Psychiat. Genet. 22, 216-217 (2012).

$39 \mathrm{Li}, \mathrm{X}$. Survey of intermarriage in rural area of southern Xinjiang province. Xinjiang Academy of Social Sciences 4, 59-66 (2012).

40 Xi, Y. L., Tian, Q., Tuerxun, T., Kaheman, K., Jiang, C. H. \& Huang, H. X. Comparison of functional magnetic resonance imaging in cerebral activation between normal Uygur 
and Mandarin participants in semantic identification task. Int. J. Clin. Exp. Med. 8, 13724-13731 (2015)

41 Siok, W. T., Niu, Z., Jin, Z., Perfetti, C. A. \& Tan, L. H. A structural-functional basis for dyslexia in the cortex of Chinese readers. Proc. Natl Acad. Sci. USA 105, 5561-5566 (2008).

42 Luciano, M., Lind, P. A., Duffy, D. L., Castles, A., Wright, M. J., Montgomery, G. W. et al. A haplotype spanning KIAAO319 and TTRAP is associated with normal variation in reading and spelling ability. Biol. Psychiatry 62, 811-817 (2007).

43 Brkanac, Z., Chapman, N. H., Matsushita, M. M., Chun, L., Nielsen, K., Cochrane, E. et al. Evaluation of candidate genes for DYX1 and DYX2 in families with dyslexia. Am. J. Med. Genet. B Neuropsychiatr. Genet 144B, 556-560 (2007).

44 Dennis, M. Y., Paracchini, S., Scerri, T. S., Prokunina-Olsson, L., Knight, J. C., Wade-Martins, R. et al. A common variant associated with dyslexia reduces expression of the KIAAO319 gene. PLOS Genet. 5, e1000436. ( (2009).

45 Pan, Y., Ma, J., Zhang, W., Du, Y., Niu, Y., Wang, M. et al. IRF6 polymorphisms are associated with nonsyndromic orofacial clefts in a Chinese Han population. Am. J. Med. Genet. A 152A, 2505-2511 (2010).
46 Fallin, D. \& Schork, N. J. Accuracy of haplotype frequency estimation for biallelic loci, via the expectation-maximization algorithm for unphased diploid genotype data. Am. J. Hum. Genet. 67, 947-959 (2000).

cc) (1) (2) $\odot$ This work is licensed under a Creative Commons Attribution-NonCommercial-NoDerivs

International License. The images or other third party material in this article are included in the article's Creative Commons license, unless indicated otherwise in the credit line; if the material is not included under the Creative Commons license, users will need to obtain permission from the license holder to reproduce the material. To view a copy of this license, visit http://creativecommons.org/ licenses/by-nc-nd/4.0/

Supplementary Information accompanies the paper on Journal of Human Genetics website (http://www.nature.com/jhg) 